\title{
Be The Help
}

David W. Callaway, MD, FACEP; E. Reed Smith, MD; Geoff Shapiro, EMT-P

A ctive Violent Incidents (AVI) are defined as high threat incidents where a person or persons are actively engaged in killing or wounding civilians at the time of first responder activation. Examples include the Boston Marathon bombing, Pulse Nightclub shooting, and Las Vegas shooting.

Penetrating trauma is the primary mechanism of injury in AVI (i.e. blast projectile or ballistic injuries). Generally, hemorrhage is the leading cause of potentially preventable death in trauma. And, as trauma is the leading cause of death for Americans aged 1-48 years, preparedness for AVIs can result in improved day-to-day community resilience.

The time to initial life saving intervention, time to stabilizing professional trauma care, and time to definitive care affect trauma-related mortality. As bystanders are nearly always the first on scene after a traumatic incident, a trained and empowered citizenry is critical to improving trauma survival.

\section{WHAT YOU CAN DO}

Intervening to save a life is not without risk and is a deeply personal decision. Generally, Good Samaritan laws protect non-professional first responders who are acting in good faith to assist a fellow citizen. If you encounter an individual with a traumatic injury, take a moment to ensure your own safety and activate the first responder system (i.e. call 911 in the US). Then, "Be the Help" until help arrives.

1. Control massive external bleeding with direct pressure, pressure dressing or tourniquet (if extremity injury).

2. Open the airway.

3. Improve breathing by covering any holes in the chest and allowing the individual to assume a position of comfort; do not force the person to lay down!

4. Keep the individual warm and in a comfortable position.

5. Provide psychological support.

Individuals with penetrating trauma to the chest and abdomen require immediate emergency medicine and trauma evaluation. Decisions to transport traumatically injured individuals in a private vehicle or nonmedical vehicle should consider at least the type of injury, the ability to provide care en route, the current situational threat, EMS response times, and distance to the hospital or trauma center.

\section{For More Information}

Committee for Tactical Emergency Casualty Care

- http://www.c-tecc.org/

- http://tecc.inquisiqr4.com/

FEMA's You are The Help Until Help Arrives Program

https://www.ready.gov/until-help-arrives

Stop the Bleed Campaign

https://www.dhs.gov/stopthebleed

\section{About the Authors}

Emergency Medicine, Operational and Disaster Medicine, Carolinas Medical Center, Charlotte, North Carolina (Callaway); Arlington County Fire Department, Emergency Medicine, The George Washington University, Arlington, Virginia (Smith); and EMS $\mathcal{B}$ Operational Medicine Training, The George Washington University, Washington, District of Columbia (Shapiro).

Correspondence and reprint requests to David W. Callaway, Emergency Medicine, Operational and Disaster Medicine, Carolinas Medical Center, 1000 Blythe Blvd, Charlotte, NC 28203 (e-mail: David.callaway@ carolinashealthcare.org). 


\section{When there is life-threatening injury, YOU can BE THE HELP until help arrives.}

Ensure your SAFETY. Call for HELP. THEN:

1 stop the BLEEDING.

Apply direct pressure to the wound, then, if needed and available, apply tourniquets or pack the wound/apply a pressure dressing. Do not pack wounds of the chest or abdomen.

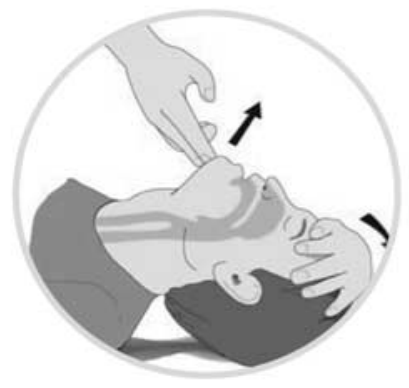

\section{2 open the AIRWAY.}

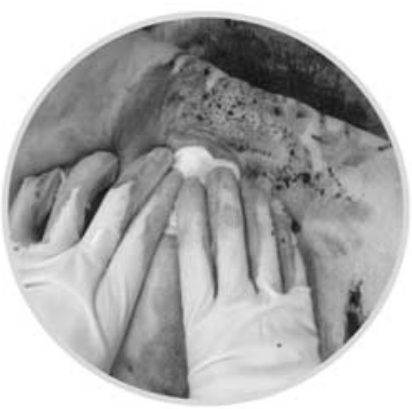

Manually clear mouth of any foreign debris. Use a chin lift/jaw thrust to open the airway if unconscious.

\section{Improve BREATHING.}

Cover any hole in the chest with anything plastic that will stop air flow, preferably a manufactured vented chest seal.

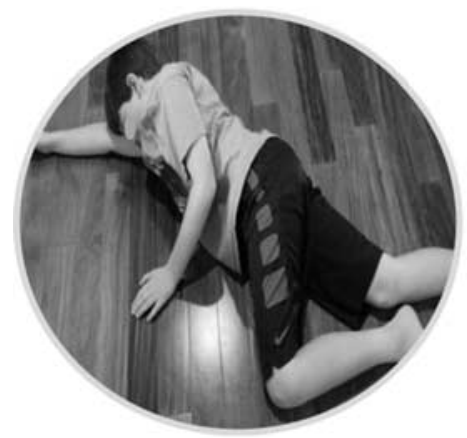

\section{Position and keep WARM.}

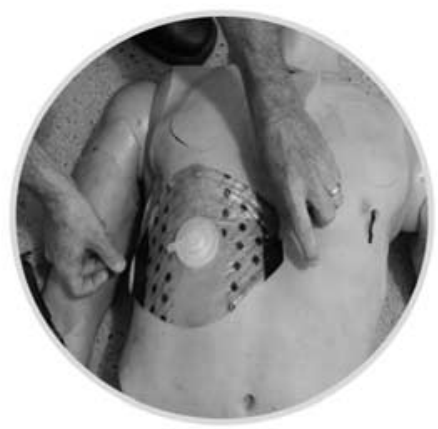

Allow the person to assume position of comfort- even if it is sitting up. If unconscious, place the person on his or her side. Cover and keep the person warm. Insulate him/her from the ground and protect from the elements.

\section{Provide PSYCHOLOGICAL support.}

Talk to the person. Tell them that help is coming! Remind them of someone or something to live for.

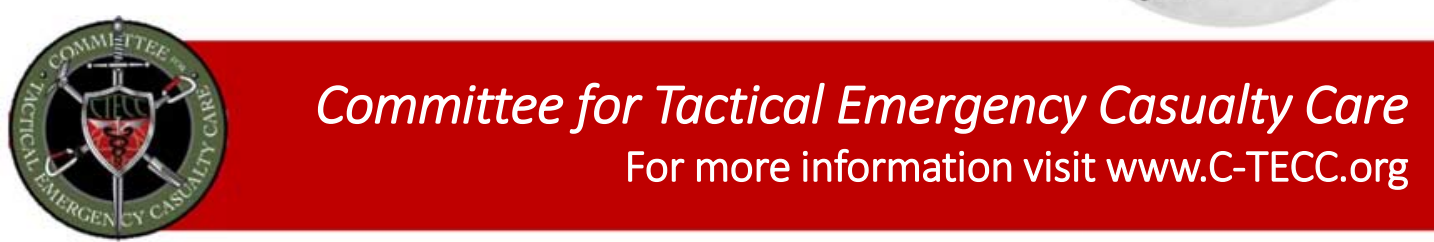

